\title{
Gezi Teknelerinin Batması Üzerine Bir Vaka Çalışması
}

\author{
${ }^{* 1}$ Hüseyin Yılmaz \\ ${ }^{1}$ Yıldız Teknik Üniversitesi, Gemi İnşaatı ve Denizcilik Fakültesi, Beşiktaş, İstanbul 34349 Türkiye
}

\begin{abstract}
Today, blue voyage, scuba diving, sport fishing and boat tours have become important tourist activities. Life safety has become the most important issue when traveling on these boats. In recent years, the safety of life has been questioned by the sinking of some boats. Over the past year, two boat overturns have occurred in the event of any accident or structural damage. There were some casualties and some injuries in the accident, and the boats were not recovered. In this study, the conditions of the sinking boats without any interference with the accident and the integrity of the boats were examined and the causes of the event were revealed. As a result of this study, suggestions were made about the measures and sanctions that should be taken by the related Administration of these boats, which have not Classification Society (Loyd) but are used for tourism purposes under 24 meters in length.
\end{abstract}

Key words: Yacht, pleasure craft, capsize, stability

\section{Özet}

Günümüzde mavi yolculuk, tüplü dalış, spor balıkçıllğı ve tekne turları önemli turizm faaliyetleri haline gelmiştir. Bu teknelerle seyahat ederken can güvenliği en önemli sorun haline gelmektedir. Son yıllarda bazı teknelerin batması ile can güvenliği sorgulanır hale gelmiştir. Son bir yıl içinde iki adet teknenin batması olayı herhangi bir kaza ve yapısal hasarın meydana gelmemesi durumunda gerçekleşti. Kazanın birinde bazı can kayıpları ve bazı yaralanmalar olmuştur, tekneler de kurtarılamamıştır. Bu çalışmada herhangi bir kazaya karışmadan ve tekne bütünlüğü bozulmadan batan teknelerin durumları incelenmiş ve olayın nedenleri ortaya konmuştur. Çalışma sonucunda özellikle klaslı olmayan ancak turizm amaçlı kullanılan ve tam boyu 24 metrenin altındaki bu teknelerle ilgili idare tarafından alınması gereken tedbirler ve yaptırımlara ilişkin öneriler sunulmuştur.

Anahtar Kelimeler: Yat, gezinti teknesi, devrilme, stabilite

\section{Giriș}

Günümüzde su sporları ve deniz turizmi yaygın olarak teknelerle birlikte yapılmaktadır. Bunlara örnek olarak mavi yolculuk, dalış, paraşütle tekne turu, Bu teknelerle yapılan seyahatlerde can güvenliği her zaman en önemli husustur. Son yıllarda herhangi bir kazaya uğramadan bazı

*Corresponding author: Address: Naval Architecture and Maritime Faculty, Department of Naval Architecture and Marine Engineering, Yildiz Technical University, 34349, Istanbul, TURKEY. E-mail address: hyilmaz@yildiz.edu.tr 
teknelerin su alarak batması ve bunlarla birlikte can kayıplarının olması bu teknelerdeki emniyet tedbirlerini veya yapısal kusurları sorgulanır hale getirmiştir. Bu çalışmada Ulaştırma ve Altyapı Bakanlığı'na bağlı Kaza Araştırma ve İnceleme Kurulu'nun yaptığı istatistiklerden [1] ve kazalarla ilgili tarafimıza ulaşan bilgi ve belgelerden yararlanarak sadece su alma nedeniyle alabora olarak batan teknelerin durumları incelenmiştir. Ayrıca çalışmada ISAR [2] ve KURT-C [3] teknelerine ait detaylı kaza analiz raporları incelenmiştir.

\section{Su Alma Nedeniyle Batan Teknelerin İncelenmesi}

$\mathrm{Bu}$ bölümde 2008-2018 yılları arasında sadece su alma nedeniyle batan 24 metrenin altındaki teknelere ait istatistikler incelenmiştir (Çizelge 2.1). Çalışmada Çizelge 2.1 de verilen teknelerden birinin jenerik bir modeli oluşturulmuş ve sadece su alma nedeniyle batmasına ait senaryolar oluşturularak en kritik durum analiz edilmiştir (Şekil 2.1).

Çizelgede verilen teknelerin bazılarına ait detaylı kaza analiz raporları kaynaklarda ayrıca verilmiştir [2,3].

Gemi ve Su Araçlarının İnşa, Tadilat ve Bakım-Onarım Yönetmeliği'ne göre [4] boyu 24 metrenin altındaki hem ticari hem de özel amaçlı teknelerin/yatların klaslı olma zorunluluğu yoktur. Ancak tekne tasarım ve üreticisinin herhangi bir Klas Kuruluşu ve İdarenin öngördüğü koşulları sağlaması istenmektedir. Dolayısıyla bu teknelerle ilgili bir kural boşluğu olmayıp eksiklik ve aksaklık olabilir. Bu çalışmada da bunların ortaya konması hedeflenmiştir.

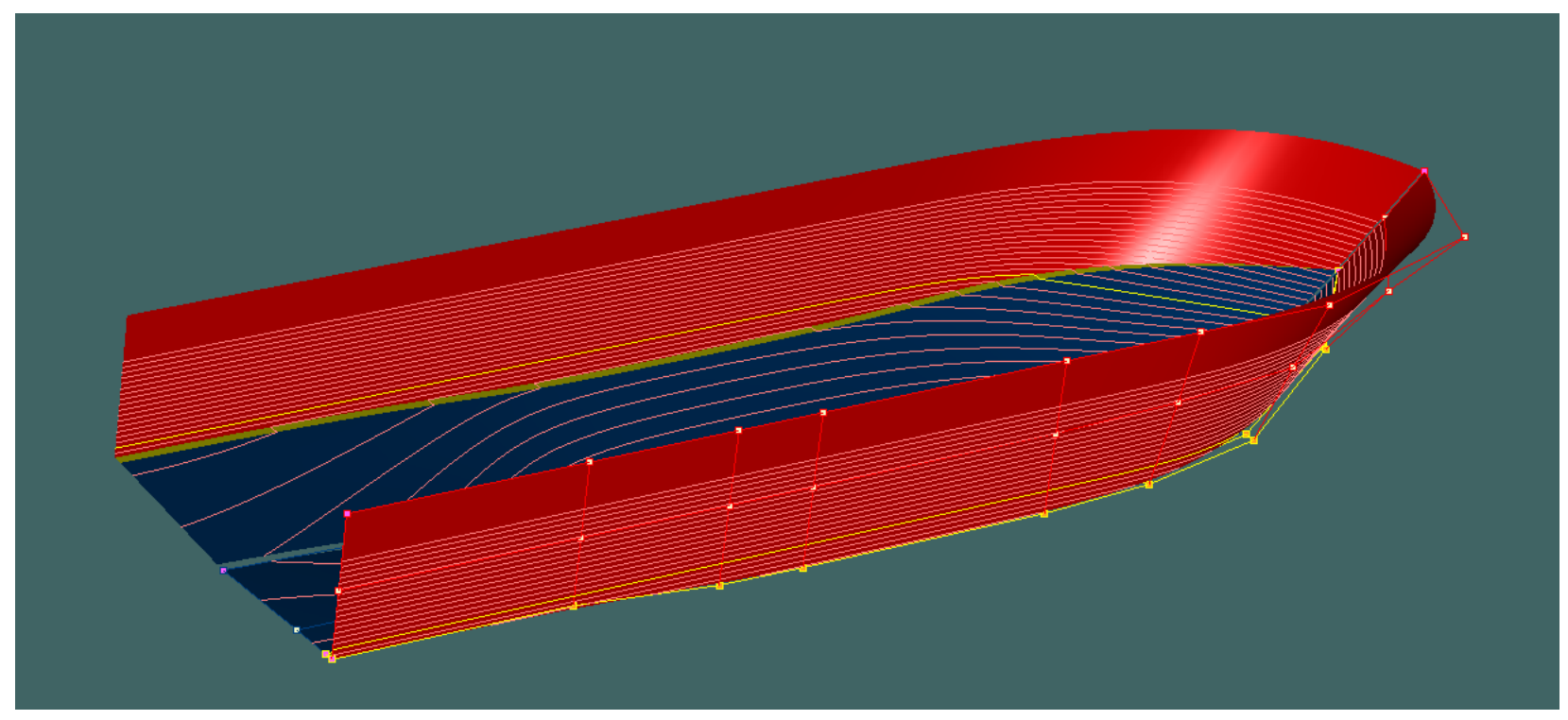

Şekil 2.1. Jenerik tekneye ait model 
Çizelge 2.1. 2008-2018 Y1lları Arasında Su Alma Nedeniyle Batan Tekneler [1]

\begin{tabular}{|c|c|c|c|c|c|c|c|}
\hline $\begin{array}{l}\text { Sira } \\
\text { No }\end{array}$ & Tarih & Kaza Bölgesi & Tekne Adı & $\begin{array}{c}\text { Tekne } \\
\text { Boyu }(\mathrm{m})\end{array}$ & Tekne Tipi & Kaza nedeni & Kaza tipi \\
\hline 1 & 02.08 .2008 & IZMIR & ALKAZAR & 19.7 & TICARI YAT & Su alma & $\begin{array}{c}\text { Alabora/ } \\
\text { Batma }\end{array}$ \\
\hline 2 & 06.08 .2008 & ANTALYA & ŞOVALYE & 14 & YOLCU MOTORU & Su alma & $\begin{array}{c}\text { Alabora/ } \\
\text { Batma }\end{array}$ \\
\hline 3 & 26.09 .2008 & ANTALYA & ÖZGE & 11.5 & YOLCU MOTORU & $\begin{array}{c}\text { Hava } \\
\text { muhalefeti }\end{array}$ & $\begin{array}{c}\text { Alabora/ } \\
\text { Batma }\end{array}$ \\
\hline 4 & 19.07.2009 & ANTALYA & $\begin{array}{l}\text { PRINCESS } \\
\text { DOĞA }\end{array}$ & 18.35 & YOLCU MOTORU & Su alma & $\begin{array}{c}\text { Alabora/ } \\
\text { Batma }\end{array}$ \\
\hline 5 & 08.02 .2010 & ÇANAKKALE & HTAO124K & 11 & ÖZEL SÜRAT TEKNESI & Su alma & $\begin{array}{c}\text { Alabora/ } \\
\text { Batma }\end{array}$ \\
\hline 6 & 07.02 .2010 & IZMIR & BİG BABA & 18.5 & YOLCU MOTORU & Su alma & $\begin{array}{c}\text { Alabora/ } \\
\text { Batma }\end{array}$ \\
\hline 7 & 24.06 .2011 & ULUSLARARASI & ROZA & 9 & ÖZEL YAT & Su Alma & $\begin{array}{c}\text { Alabora/ } \\
\text { Batma }\end{array}$ \\
\hline 8 & 13.06 .2011 & IZMIR & MIRANDA & 9 & ÖZEL YAT & Su alma & $\begin{array}{c}\text { Alabora/ } \\
\text { Batma }\end{array}$ \\
\hline 9 & 08.05 .2011 & IZMIR & --- & 5 & FIBER TEKNE & Bilinmiyor & $\begin{array}{c}\text { Alabora/ } \\
\text { Batma }\end{array}$ \\
\hline 10 & 09.12 .2012 & IZMIR & PAPAĞAN 1 & 17 & FIBER TEKNE & $\begin{array}{c}\text { Hava } \\
\text { muhalefeti }\end{array}$ & $\begin{array}{c}\text { Alabora/ } \\
\text { Batma }\end{array}$ \\
\hline 11 & 08.11 .2012 & IZMIR & HAPPY & 17 & ÖZEL YAT & $\begin{array}{c}\text { Hava } \\
\text { Muhalefeti }\end{array}$ & $\begin{array}{c}\text { Alabora/ } \\
\text { Batma }\end{array}$ \\
\hline 12 & 30.06 .2012 & IZMIR & CELESTINA & 17 & YAT & Su alma & $\begin{array}{c}\text { Alabora/ } \\
\text { Batma }\end{array}$ \\
\hline 13 & 10.06.2012 & IZMIR & YECE & 3.95 & ÖZEL YAT & ALABORA & $\begin{array}{c}\text { Alabora/ } \\
\text { Batma }\end{array}$ \\
\hline 14 & 28.04 .2012 & ANTALYA & $\begin{array}{c}\text { MERT } \\
\text { KAPTAN-7 }\end{array}$ & 4.64 & ÖZEL YAT & Su alma & $\begin{array}{c}\text { Alabora/ } \\
\text { Batma }\end{array}$ \\
\hline 15 & 30.01 .2012 & IZMIR & SWEETY-2 & 12.7 & TICARI YAT & Su alma & $\begin{array}{c}\text { Alabora/ } \\
\text { Batma }\end{array}$ \\
\hline 16 & 05.10 .2013 & IZMIR & $\begin{array}{l}\text { BLUE } \\
\text { INFINITY }\end{array}$ & 11.9 & ÖZEL YAT & SU ALMA & $\begin{array}{c}\text { Alabora/ } \\
\text { Batma }\end{array}$ \\
\hline 17 & 13.12 .2013 & ISTANBUL & ISAR & 11.5 & ACENTE BOTU & SU ALMA & $\begin{array}{c}\text { Alabora/ } \\
\text { Batma }\end{array}$ \\
\hline 18 & 01.12 .2015 & IZMIR & ALİ BABA-08 & 10 & TICARI YAT & SU ALMA & $\begin{array}{c}\text { Alabora/ } \\
\text { Batma }\end{array}$ \\
\hline 19 & 23.08.2015 & ANTALYA & OĞUL N & 18 & TICARI YAT & SU ALMA & $\begin{array}{c}\text { Alabora/ } \\
\text { Batma }\end{array}$ \\
\hline 20 & 09.02 .2015 & ISTANBUL & VALENTINE & 20 & ÖZEL YAT & SU ALMA & $\begin{array}{c}\text { Alabora/ } \\
\text { Batma }\end{array}$ \\
\hline 21 & 08.01 .2015 & IZMIR & $\begin{array}{l}\text { GELIN } \\
\text { GEZELIM }\end{array}$ & 11 & $\begin{array}{c}\text { GEZINTI (TENEZZÜH) } \\
\text { TEKNESI }\end{array}$ & SU ALMA & $\begin{array}{c}\text { Alabora/ } \\
\text { Batma }\end{array}$ \\
\hline 22 & 03.09 .2016 & ANTALYA & KURT-C & 24 & $\begin{array}{c}\text { GEZINTI (TENEZZÜH) } \\
\text { TEKNESI }\end{array}$ & $\begin{array}{c}\text { HAVA } \\
\text { MUHALETI }\end{array}$ & $\begin{array}{c}\text { Alabora/ } \\
\text { Batma }\end{array}$ \\
\hline 23 & 02.08.2017 & MUĞLA & ANEMONE & 20 & ÖZEL YAT & SU ALMA & $\begin{array}{c}\text { Alabora/ } \\
\text { Batma }\end{array}$ \\
\hline 24 & 02.04 .2018 & MUĞLA & MERMAID & 24 & DALGIÇ TEKNESI & SU ALMA & $\begin{array}{c}\text { Alabora/ } \\
\text { Batma }\end{array}$ \\
\hline
\end{tabular}




\section{Jenerik Tekne Modelinin Oluşturulması}

Bu kısımda batan teknelerden birisinin jenerik modeli yapılarak su alma durumuna ait stabilite analizleri yapılmıştır (Şekil 3.1). Jenerik teknenin gerçek stabilite kitapçığındaki yükleme durumlarının üzerine su alma senaryoları uygulanmıştır. Bu senaryolar esnasında tekneye muhtemel su girebilecek bölgeden su girişi varsayılmış ve kademeli olarak suyun ilerlediği varsayılmıştır. $\mathrm{Bu}$ durum bir çeşit teknenin yaralanma senaryolarına benzemektedir. $\mathrm{Bu}$ senaryolarda teknenin hangi koşullarda batabileceği senaryosu öngörülerek analiz edilmiştir. Öncelikle tekne modelinin mevcut stabilite kitapçığında verilen tam yükleme durumu (en ekstrem senaryo, maksimum yolcu alma durumu) dikkate alınarak yapılan analizlerinde oldukça stabil olduğu tespit edilmiştir.

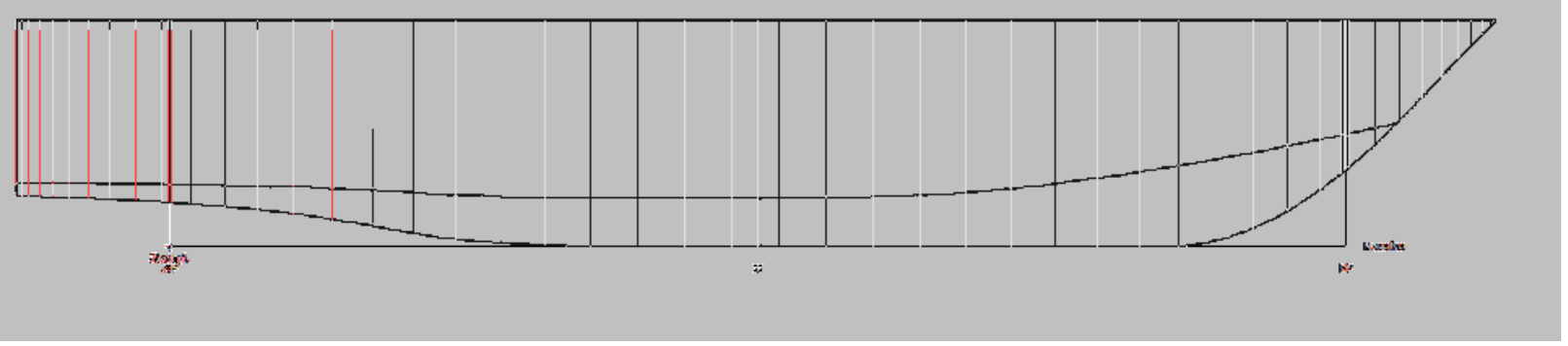

Şekil 3.1. Jenerik teknenin profil resmi

Illk senaryo: Tekne tam yüklü kıç kapak açık ve kıç taraftan itibaren ilk su geçmez perdeye kadar su girişi olduğu varsayılmıştır. Bu durumda stabilite açısından herhangi bir sorun olmayıp teknenin batması söz konusu değildir (Şekil 3.2).

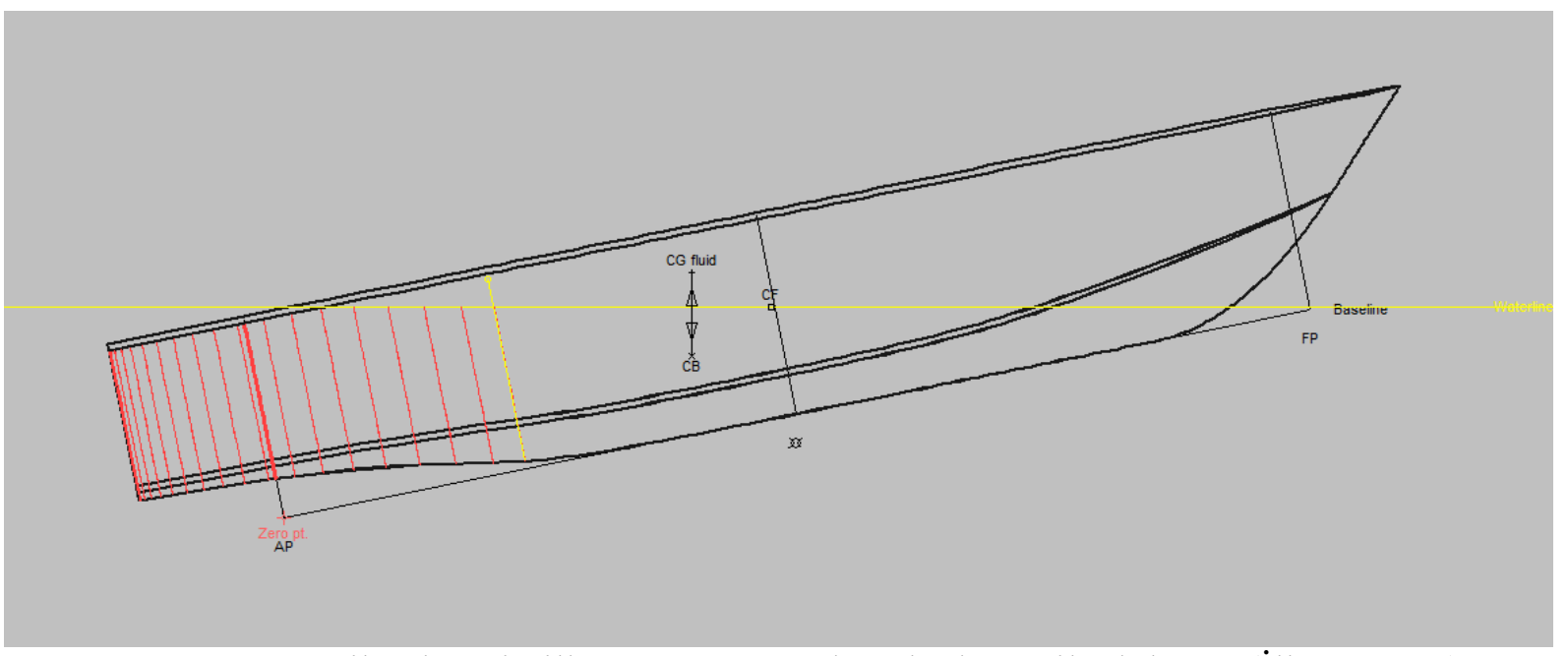

Şekil 3.2. Jenerik teknenin ilk sugeçmez perdeye kadar su ile dolması (İlk Senaryo) 
İkinci senaryo: Tekne tam yüklü kıç kapak açık ve kıç taraftan itibaren makine dairesi baş perdesine kadar su girişi olduğu varsayılmıştır. Bu durumda tekne aşırı derecede kıça trim yapmakta, aşırı atalet moment kaybından ve serbest yüzey etkisinden dolayı tekne kıç üstü batmaktadır. Bu duruma ait stabilite hesap sonuçları ve teknenin durumu Şekil 3.3'te görülmektedir.

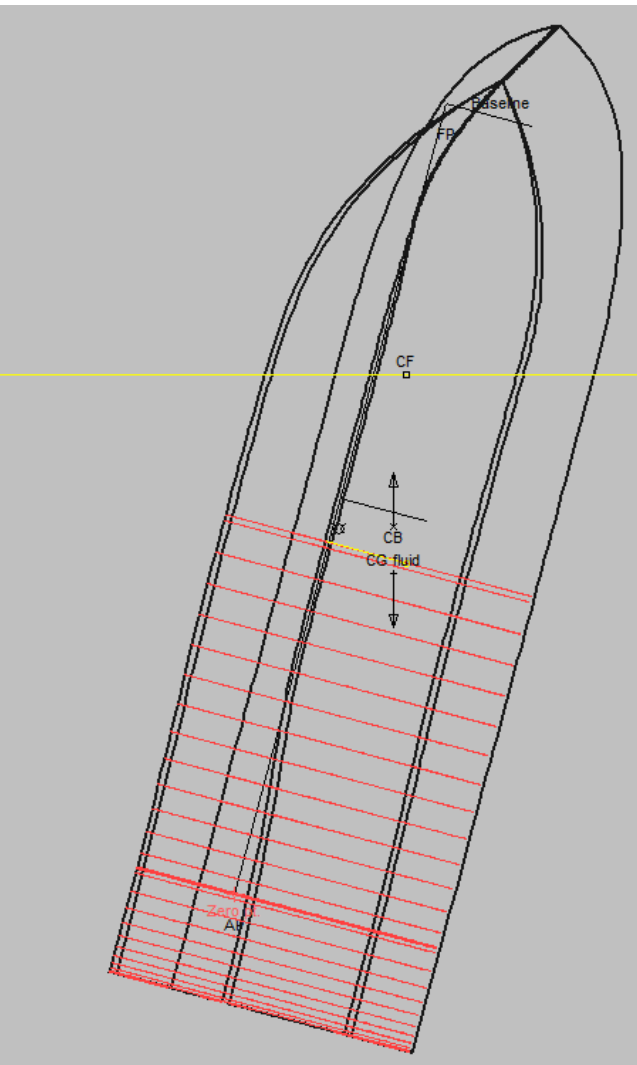

\begin{tabular}{|c|c|}
\hline Draft Amidships m & 19,748 \\
\hline Displacement $\mathrm{t}$ & 124,5 \\
\hline Heel deg & $-124,1$ \\
\hline Draft at FP m & $-43,448$ \\
\hline Draft at AP m & 82,944 \\
\hline Draft at LCF m & $-1,301$ \\
\hline Trim (+ve by stern) m & 126,392 \\
\hline WL Length $\mathrm{m}$ & 19,000 \\
\hline Beam max extents on WL $\mathrm{m}$ & 3,969 \\
\hline Wetted Area $\mathrm{m}^{\wedge} 2$ & 300,572 \\
\hline Waterpl. Area $\mathrm{m}^{\wedge} 2$ & 8,159 \\
\hline Prismatic coeff. (Cp) & 0,279 \\
\hline Block coeff. (Cb) & 0,102 \\
\hline Max Sect. area coeff. $(\mathrm{Cm})$ & 0,366 \\
\hline Waterpl. area coeff. (Cwp) & 0,108 \\
\hline LCB from zero pt. (+ve fwd) m & 9,195 \\
\hline LCF from zero pt. (+ve fwd) m & 12,664 \\
\hline $\mathrm{KB} \mathrm{m}$ & 2,207 \\
\hline KG fluid $\mathrm{m}$ & 2,900 \\
\hline BMt m & 0,116 \\
\hline BML m & 0,034 \\
\hline GMt corrected m & 1,209 \\
\hline GML m & 1,127 \\
\hline KMt m & 2,190 \\
\hline KML m & 2,202 \\
\hline Immersion (TPc) tonne/cm & 0,084 \\
\hline MTc tonne.m & 0,074 \\
\hline $\mathrm{RM}$ at $1 \mathrm{deg}=\mathrm{GMt}$.Disp. $\sin (1)$ tonne. $\mathrm{m}$ & 2,628 \\
\hline 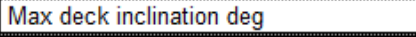 & 98,3491 \\
\hline Trim angle (+ve by stern) deg & 81,4510 \\
\hline
\end{tabular}

Şekil 3.3. Jenerik teknenin makine dairesi baş perdesine kadar su ile dolması (İkinci Senaryo)

$\mathrm{Bu}$ iki senaryo dikkate alındığında sadece kıç kapağın açık olması değil bununla birlikte ilk sugeçmez perde üzerindeki kapının da açık olma ihtimali çok büyük olasılıktır. Ancak kıç bölme ile birlikte makine dairesine de su girişi ile teknenin batması söz konusu olmaktadır.

Bölgedeki deniz durumunun da 4'ün üzerinde olduğu varsayıldığında ki bu deniz durumunda muhtemel dalga yüksekliğinin 1.5 metrenin üzerinde olduğu değerlendirildiğinde teknenin kıç tarafından kolaylıkla su girişinin gerçekleşeceği görülecektir.

Bu jenerik teknenin planlarından gemi kıç tarafında yer alan platformun hizasında yüklü su hattının olduğu, kaportanın ise aynanın tam ortasında yer aldığı ve küçük bir eşik yüksekliğinden sonra başladığı anlaşılmaktadır. Gemi kıç tarafında yer alan platformun, su hattının yaklaşık $25-30 \mathrm{~cm}$ üstünde olduğu görülmektedir. Özellikle dalgalı deniz durumunda, dalgaların kolaylıkla kıç ayna üzerine geleceği ve kaportanın açık olması durumunda ise içeri gireceği görülecektir. Kıç 
kaportanın açılması ile engelsiz şekilde yoğun su girişi olacağı ve giren suyun engelsiz şekilde makine dairesi kıç perdesine kadar büyük bir hacme dolabileceği tespit edilmiştir. Yürürlükteki mevzuata ve klas kurallarına göre gemide bulunan açıklıkların minimum eşik yükseklikleri en az $45 \mathrm{~cm}$ olmak zorundadır. Bu teknede bu kurala uyulsa bile kaportalar açıldığında olay anındaki deniz durumunda suyun kolaylıkla kaporta kapılardan makine dairesine ve geminin kıç tarafındaki hacme dolacağı aşikardır.

\section{Sonuçlar}

$\mathrm{Bu}$ çalışmada kullanılan jenerik teknenin batmasına neden olan hususun kıç platformdaki kaportanın (kapak) açık olması sonucu teknenin kıç bölgesine deniz suyunun 4-6 deniz durumunda oluşan 1.5-2.5 metre yüksekliğindeki dalganın girmesi ve akabinde teknenin kıça trim yapması bunun devaminda tekneye daha fazla deniz suyunun girmesi ve kuvvetle muhtemel makine dairesine açılan kıç sugeçmez perde üzerindeki kapının da açılması neticesinde makine dairesinin de su ile dolması ve teknenin daha fazla kıça trim yapması, sephiye kaybı, bu bölümün denizle iştirakli olduğundan atalet momenti kaybı ve serbest yüzey etkisi ile birlikte teknenin çok hızlı bir şekilde kıç üstü battığı kanaatine yapılan analizlerle varılmıştır.

Sadece bu kazada bile görüldüğü üzere teknelerin su alarak batmasına bir dizi unsurlar neden olmaktadır. Bunlardan bir kısmı tekne inşa kurallarının revize edilmesi ile ilgili, bir kısmı ise tekne kullanımına yönelik operasyonel hatalar sayılabilir.

24 metrenin üzerindeki klaslı gemilere uygulanan kuralların güvenlikle ilgili kısımları 24 metrenin altındaki teknelere de uygulanmalıdır. Bunların başında kapı/kaporta eşik yüksekliklerinin sugeçmez şekilde kurallara uygun olması, kapı/kaporta açık uyarı ikazlarının mutlaka olması, teknelerin plan ve hesaplarının doğru şekilde yapıldığının etkin bir şekilde kontrol edilmesi.

\section{Kaynaklar}

[1] Ulaştırma ve Altyapı Bakanlığı, Kaza Araştırma ve İnceleme Kurulu İstatistikleri, http://www.kaik.gov.tr.

[2] “İSAR İsimli Acente Botunun Batmasına İlişkin Deniz Kazası İnceleme Raporu”, Ulaştırma ve Altyapı Bakanlığg, Kaza Araştırma ve İnceleme Kurulu, Rapor No. 14/DNZ-4/2016, 13 Aralik 2013.

[3] "KURT C İsimli Geminin Batması Sonucu Meydana Gelen Deniz Kazasına İlişkin İnceleme Raporu", Ulaştırma ve Altyapı Bakanlığı, Kaza Araştırma ve İnceleme Kurulu, Rapor No. 36/DNZ-05/2017, 3 Eylül 2016.

[4] Gemi Ve Su Araçlarının İnşa, Tadilat Ve Bakım-Onarım Yönetmeliği, 7 Kasım 2015 tarih ve 29525 say1lı resmi gazete. 